\title{
Jornalismo e movimentos em rede: a emergência de uma crise sistêmica
}

\section{Journalism and networked movements: the emergence of a systemic crisis}

\author{
Ronaldo Cesar Henn \\ Mestrado e doutorado em Comunicação e Semiótica pela PUCSP, professor adjunto no PPG em Ciências da Comunicação da \\ Unisinos. \\ $<\underline{\text { henn.ronaldo@gmail.com> }}$
}

Felipe Moura de Oliveira

Jornalista, mestre em Ciências da Comunicação pela Unisinos e doutorando no mesmo programa.

$<$ felipecomunica@gmail.com>

\section{RESUMO}

\begin{abstract}
O artigo oferece desenho conceitual do que se postula ser a crise enfrentada pelo jornalismo contemporâneo, cujo processamento se dá em plataformas distintas e convergentes de produção e circulação da informação. Entende-se a crise a partir de perspectiva sistêmica associada a conceitos advindos da Teoria Geral dos Signos, de C. S. Peirce, e da Semiosfera, de Yuri Lotman. Compreende-se o jornalismo como um sistema aberto, dinâmico, complexo e não linear, que se transforma potencialmente na interação com outros sistemas de produção de sentido, como os que são agenciados pelas redes sociais digitais. A concretização do debate se dá pelo cotejamento dessa reflexão aos casos observados em pesquisas atualmente empreendidas pelos autores deste trabalho.
\end{abstract}

Palavras-chave: Crise. Ciberacontecimento. Movimentos de ocupação global.

\begin{abstract}
The paper provides conceptual design than it is postulated to be the crisis faced by contemporary journalism, whose processing occurs in distinct and converging platforms of production and circulation of information. It is understood the crisis from a systemic perspective associated at concepts of General Theory of Signs of C. S. Peirce and of the Semiosphere of Yuri Lotman. It is understood journalism as an open, dynamic, complex and nonlinear system, which turns potentially when it interacts with other systems of meaning production, as those agencied by digital social networks. The realization of the debate happen by mutual comparison of this reflection to cases observed in research currently undertaken by the authors of this work.
\end{abstract}

Keywords: Crisis. Cyberevent. Global occupation movements.

\section{Introdução}

A ideia de que existe uma crise no jornalismo contemporâneo proliferase a partir de diferentes fontes, e tem gerado reflexões no campo profissional (Ramonet, 2012; Lafuente, 2012)'. É necessário, entretanto, precisar a

1 Ignacio Ramonet (2012, p. 15), do Le Monde Diplomatique, da França, diz que: “O planeta mídia está sofrendo um traumatismo de amplitude inédita. $\mathrm{O}$ impacto do meteorito internet, semelhante àquele que fez desaparecer os dinossauros, tem provocado uma mudança radical de todo o ecossistema midiático". E Gumersindo Lafuente (2012, p. 212), do El País, da Espanha, avalia que: "Agora, e isto por 
natureza dessa crise com dados processuais advindos de práticas jornalísticas em distintas e convergentes plataformas, que se convertem em palco de transformações significativas.

Ao mesmo tempo, mobilizações sociais de temperaturas diversas, mas conectadas em redes digitais, desencadeiam novas articulações e constituições na relação acontecimento/notícia, cuja propulsão produz tensões. A partir desses pressupostos, o presente artigo propõe-se a formular um desenho conceitual para o entendimento da crise e cotejá-lo com inferências de pesquisas em andamento, empreendidas pelos autores deste texto, que buscam entender esse universo complexo nas suas processualidades, configurações e linguagens.

Compreende-se a crise a partir de uma perspectiva sistêmica, notadamente oriunda das transformações introduzidas na Teoria Geral dos Sistemas a partir da investigação dos chamados sistemas abertos, dinâmicos e fora do equilíbrio (Mainzer, 1994; Prigogine, 1996; Bunge, 1999). Essa perspectiva, sobretudo através da aventura enciclopédica de Edgar Morin com a obra "O Método" (1986a, 1986b, 1986c, 1998), popularizou-se com o nome de Ciências da Complexidade ou pensamento complexo, situação que gerou apropriações de quilates distintos, algumas diluidoras do caráter conceitual rigoroso em jogo. A ela são associados aqui conceitos da Teoria Geral dos Signos, de C. S. Peirce, e da Semiosfera concebida por Yuri Lotman.

Trata-se de um exercício conceitual, que não deixa de trazer à reflexão indícios apurados em investigações acerca de ciberacontecimentos que se processam em rede e tem características muito peculiares (Henn, 2013b) e fenômenos sociais que envolvem os movimentos de ocupação global, com ecos no Brasil nas jornadas de junho de 2013 (Oliveira e Henn, 2013b). Num primeiro momento, apresenta-se a perspectiva sistêmica como lugar epistêmico, seguida pela definição da crise - e da semiose como elemento catalizador e a contextualização do jornalismo nesse processo para, por fim, apontar as tensões que são geradas às práticas jornalísticas e propor considerações.

\section{Sistemas abertos como perspectiva lógico-teórica}

A perspectiva dos sistemas abertos nasce da percepção de que processos físico-químicos do universo são pautados por parâmetros significativos de indeterminação e incerteza (Mainzer, 1994; Morin, 1986a). A concepção de um

uma lado é um grande drama, mas, por outro, uma grande oportunidade, perdemos esse monopólio da intermediação. Muita gente está disputando, em alguns casos com vantagem, e isto tem nos obrigado a reinventar o nosso ofício". 
universo fechado e previsível, desenhado pela mecânica clássica, é confrontada com outras, principalmente as que incorporaram desdobramentos da segunda lei da termodinâmica, a entropia (Harrisom, 1975). O desgaste energético implicado na entropia, num universo como sistema fechado, produziria a morte térmica, entropia máxima ou caoticidade total.

As investigações de fenômenos biológicos, entretanto, abriram novos horizontes de constatações: em que pese a tendência à entropia acoplada a um direcionamento do tempo de comportamento irreversível (Prigogine, 1996), existem sistemas capazes de revertê-la, gerando organização localizada. São sistemas auto-organizacinais ou autopoiéticos, que Gell-Mann (1996) designa como "sistemas adaptativos complexos". Entre suas principais características destaca-se o fato de serem desdobramentos de singularidades pautadas pelo acaso (a vida na terra é o grande exemplo), vulneráveis às transformações do meio ambiente (exatamente por serem abertos, dinâmicos e dependerem energeticamente ou informacionalmente do meio externo) e sujeitos a flutuações com potencial de produzirem transformações significativas no sistema (Viera, 1996). A tendência à permanência, porém, pode ser garantida pela força auto-organizacional do sistema.

A Matemática do Caos (Gleick, 1988; Stewart, 1989), a Geometria dos Fractais (Barnsley, 1998; Liebovitch, 1998) e a Teoria das Estruturas Dissipativas (Prigogine e Stengers, 1994) estão entre os modelos teóricos desenvolvidos ao longo do Século XX que endossam essa perspectiva sistêmica. Esses sistemas, mesmo que naveguem no aberto e na indeterminação, possuem padrões de similaridade e de replicação, dinâmicas que elevam seus graus de complexidade. Existe um conjunto de condições inicias que disparam processos regidos por aquilo que o meteorologista, matemático e filósofo estadunidense, Edward Norton Lorenz, definiu como "atrator estranho". Mackenzie (2005) fala em "sensibilidade às condições iniciais", que podem ser entendidas como uma consequência do número incalculável de possibilidades que surgem quando um grande número de entidades interage. Em outras palavras, a singularidade - que também se pode associar ao conceito de acontecimento (Henn, 2010) - gera alta complexidade, mas vinculada a estruturalidades que, no campo semiótico, entende-se por códigos.

A ideia de que sistemas gerados pela espécie humana, como sociedade, cultura e linguagem, comportam-se como sistemas desse porte e com alto grau de complexidade, ganhou força, sobretudo a partir dos Anos 1970 (Chardim, 1999; Morin, 1975; Morin E Piatteli-Palmarini, 1945; 1998; Prigogine, 1976; Vieira, 1994; Langer, 1989; Bunge, 1979; Szamosi, 1988). A capacidade auto- 
reprodutora dos códigos culturais e linguísticos - que estão armazenados em uma mente coletiva, abstrata, que Chardim (1999) designou como noosfera e mais tarde Yuri Lotman (1996) conceituou como semiosfera - é um indício notável desse comportamento. E como os demais sistemas, são fortemente vulneráveis a flutuações críticas que podem, até mesmo, dizimá-lo.

Todos os sistemas possuem parâmetros dos quais dependem para sua plena processualidade. A conectividade está entre eles: o sistema só existe na medida em que elementos conectam-se e compartilham coisas. Mario Bunge (1979) define o sistema como um agregado de elementos que partilham entre si alguma coisa em comum. Os objetos concretos estão conectados entre si de diversas maneiras. Somente o universo como um todo não está, a princípio, conectado com outras coisas. Mas o universo é um sistema de sistemas e não um mero agregado; todos os seus componentes interagem com outros componentes, seja direta ou indiretamente (Bunge, 1999).

O que diferencia um sistema de um mero agregado ou conjunto é uma estrutura, isto é, um conjunto de relações entre componentes do sistema ou de operações sobre o mesmo.

Consideremos um sistema sem um instantet dado. Chamaremos $C(s, t)$
a composição ou coleção de todas as partes de $s$ em $t$. Chamaremos
de $E(s, t)$ o entorno de $s$ em $t$, ou seja, a coleção de todas as coisas
que, sem estar em $C(s, t)$, atuam sobre s ou estão sujeitas a ação de
$s$ no tempo. Dado que os componentes do sistema atuam entre si,
$s$ tem uma endoestrutura. Esta é a coleção de todas as relações -
em particular os enlaces ou conexões - entre vários componentes
(Bunge, 1999, p. 15).

Desse desenho emerge a ideia de que um enlace ou conexão entre duas coisas é uma relação que sempre modifica ambas. É nesse cenário sistêmico que se conceitua agora a ideia de crise proposta. Existe um parâmetro sistêmico chamado estruturalidade, que corresponde aos nexos que o sistema vai estabelecendo num processo auto-organizacional. Em Prigonine (1996), esta estruturalidade passa necessariamente pela instituição do tempo que, nos processos entrópicos, apresenta-se irreversível. O crescimento da entropia designa, pois, a direção do futuro, quer no nível de um sistema local, quer no nível do universo como um todo.

Ao produzirem organização localizada para o controle da entropia, na condição de abertos e dinâmicos, os sistemas geram novos processos. 


\begin{abstract}
Porque além de serem abertos, quando se considera uma célula ou uma cidade, percebe-se que estes sistemas vivem de sua abertura. A cidade e a célula morrerão se isoladas do seu meio, pois são uma espécie de encarnação dos fluxos que se transformam continuamente (Prigogine, 1996, p. 102).
\end{abstract}

Quanto mais complexo o sistema, mais vulnerável será às flutuações e crises e mais intensa será sua força auto-organizacional com grande carga informativa (Henn, 2013a) e essa força produz uma geração de estruturalidades (Prigogine, 1996). Tratam-se de estruturas dissipativas, porque o sistema só garante sua permanência via auto-organização se dissipar, como se ficasse em um estado contínuo de meta-estabilidade (Viera, 1996). Para Urry (2005), são ilhas de nova organização dentro de um mar de desordem, que se mantém ou mesmo aumenta sua organização à custa da entropia total.

\title{
Uma definição de crise
}

É esse o sentido da crise que defende-se: uma flutuação intensa, provocada por novos modos de conectividade que transformam os processos como um todo. Mas quando ultrapassam os parâmetros críticos, amplificam as flutuações, gerando crises que obrigam o sistema a avançar. Alguns sistemas podem sucumbir. Ao vencerem uma crise, porém, ressurgem reorganizados, reestruturados, e talvez com a identidade modificada.

Esse comportamento sistêmico possui grande semelhança nos modos como o semioticista russo Yuri Lotman (1996) desenha o conceito de semiosfera. Trata-se do espaço de confluência e metabolização de todas as semioses, ou seja, dos processos que produzem sentidos na sociedade. Antes de Lotman, Tales de Chardin (1988) havia cunhado o termo noosfera: espaço em que as ideias e realizações humanas (inclusive na sua dimensão tecnológica) ganham vida e se proliferam. Morin (1998) segue essa designação e fala em realidade noológica, submetida a uma dialógica ininterrupta de ordem/desordem/ organização em que as ideias nascem, transformam-se e sucumbem. O que a semiosfera traz de distinto é uma materialidade semiótica, produzida pelo que os semioticistas ligados a Lotman e a Escola de Tartu chamam de textos da cultura.

Essa materialidade organiza-se a partir de uma estruturalidade que a própria cultura produz (Lotman e Uspenskii, 1981). Mesmo sem utilizarem essa designação, eles estão propondo um espaço semiótico como um sistema autoorganizacional (Henn, 2013a). Esse espaço não é homogêneo, ao contrário. É regido por códigos e flutuações muitas vezes conflitivas. "A cultura exclui 
continuamente do seu próprio âmbito determinados textos", ensinam Lotman e Uspenkii (1981, p. 41), propondo que há um espaço extra-sistêmico, que chamam de "fundo de não cultura", em que extratos culturais são invisibilizados ou silenciados.

Na sua última obra, "Cultura e Explosão”, Lotman (1999) precisa melhor essas relações ao focar-se no que entende como regiões de fronteiras. Aquilo que dormita nos espaços extra-sistêmicos continua pulsando e, através das permeabilidades fronteiriças e operações de tradução, pode gerar outros códigos, estruturalidades e transformar o sistema. Tais processos podem ser lentos, graduais, ou explosivos, convulsivos. Quando entram nessa última categoria, há, segundo Lotman, um elevado aumento de semioticidade social.

Bergé, Pomeau e Dubois-Gance (1995) lembram que as sociedades humanas oferecem inúmeros exemplos de transformações brutais e buscam entendê-las a partir de padronizações sistêmicas. Kauffman (1995, p. 237-238) assegura que processos dessa natureza têm sempre forte componente de caoticidade: "Uma sociedade com trocas reduzidas pode manter-se em estado quase estacionário, sem progresso, mas também sem grande catástrofe, ao passo que o aumento das trocas permite passar bruscamente a uma dinâmica muito mais rica e complexa", acentua o autor, o que faz lembrar a máxima de que sistemas fechados podem permanecer, mas sempre serão os mesmos. Para Kauffman, é bem possível que a Revolução Industrial deva-se mais efetivamente ao aumento de trocas que viabilizou do que aos inventos propriamente ditos.

Essa ideia é confluente aos processos semiosféricos propostos por Lotman. Na medida em que novas conectividades surgem, outros códigos estabelecem-se com fluxos de semiose distintos, que geram outras possibilidades de estruturalidade: esse é o desenho de uma crise que não tem, a rigor, uma conotação negativa, destrutivo, mas, ao contrário, pode apontar para transformações alvissareiras.

No projeto sistêmico de Niklas Luhmann (1995), a comunicação é elemento constituinte da sociedade, mas também oferece um lugar na ordem social à tecnologia, técnicas e artefatos. Só que nessa perspectiva a tecnologia pode levar a uma redução da complexidade, fora o fato de que o acoplamento desenhado pelo autor para falar de interelações entre sistemas não viabiliza a força processual e crítica de um sistema aberto e dinâmico. No modo como se está entendendo a crise, a tecnologia, sobretudo pelas apropriações sociais, possui um caráter ativo, como uma espécie de mente auto-organizacional muito próxima daquilo que Bruno Latur (2008) compreende como pensamento não humano nas ferramentas que viabilizam as conexões em rede. Não se 
trata, a rigor, de uma novidade, na medida em que C. S. Peirce (2002) já tinha a compreensão de mente como qualquer coisa que processasse informação, independentemente do suporte.

\section{Semioses difusas no âmago da crise}

É em Peirce (2002) que o conceito de semiose ganha estatura definitiva. Todo o signo vincula-se a um objeto a partir de uma determinação lógica: o signo só existe em função da sua capacidade de representar, apontar ou sugerir um objeto, que, por conta disso lhe determina. E objeto não é necessariamente uma coisa; pode ser um sentimento, uma impressão, algo imaginado e não verbalmente dizível. Mas o signo só se completa na medida em que ele gera um interpretante, outro signo que se vincula ao mesmo objeto. E o interpretante gera outros e outros, num processo de potencialidade infinita.

Há, nesse jogo, uma dupla atividade do signo que, ao mesmo tempo representa e produz interpretação. Colapietro (2004) lembra que os objetos não são totalmente mudos, mas a inteligibilidade de tudo o que é mudo, no sentido estrito, é inseparável da capacidade do objeto ou coisa em questão de revelar-se em seus efeitos sobre nós e os outros seres sensíveis pela mediação do signo.

Os interpretantes podem ter caminhos diferentes por conta daquilo que Peirce chama de "experiência colateral": os repertórios que as mentes interpretantes acumulam e são acionados nos enquadramentos da produção de sentido. Do mesmo modo, os signos são articulados em codificações diversas (implicadas no fundamento do signo) que podem, tendencialmente, produzir certos direcionamentos de semiose (Henn, 2002). São processos movidos por comportamento sistêmico muito próximo do que se desenha na perspectiva acima assinalada. Processos estocásticos, sujeitos à caoticidade e a indeterminação (Merrel, 2001). Os códigos em que os signos articulam-se, alguns mais rigorosos e outros bastante porosos, funcionam como atratores estranhos num mapa de estados (Henn, 2002). Aproximando-se o conceito de semiose em Peirce com o de semiosfera de Lotman, pode-se inferir que, por conta dessas características, o espaço semiótico é um lugar de disputas de sentido propulsionado por semioses que não são, a rigor, deterministas. Os fluxos dessas semioses, disparadas por novos processos de conectividade, podem gerar flutuações com grandes níveis de tensão, produzindo situações críticas.

O jornalismo é um sistema social de grande imponência. É um espaço institucional de mediação social que tem, como principal atribuição, a 
transformação do acontecimento em narrativas inscritas em códigos historicamente constituídos. Essa atividade discursiva (Charaudeau, 2006; Benetti, 2010) ou semiótica (Henn, 1996) detém a prerrogativa de organizar, selecionar e hierarquizar os acontecimentos do mundo a partir de enquadramentos que se vinculam às conexões delicadas do sistema jornalístico com os diversos sistemas sociais, destacando-se a predominância de vínculos mais comprometidos com o Capital e os setores de poder político (Oliveira, 2012).

Tradicionalmente a semiose da notícia segue um percurso linear, que começa na produção de pauta, passa pelo trabalho de apuração do repórter, redação do texto, edição do material e culmina na veiculação. Nos radiojornais e telejornais ainda há algum espaço de imediaticidade e repercussão instantânea, mas, nos formatos impressos, as semioses produzidas pelas narrativas jornalísticas assumem uma temporalidade mais esgarçada. Quando os jornais migram para a internet e assumem características como a hipertextualidade, instantaneidade, multimidalidade e interatividade (Palácios e Noci, 2009; Machado e Palácios, 2003; Schwingel, 2012; Barbosa, 2007; Mielniczuk, 2003) os fluxos da semiose também iniciam processos de transformação.

Com a consolidação das redes digitais de comunicação², e, por consequência, as redes sociais, essas transformações atingem patamares inéditos, com a possibilidade dos sentidos serem rapidamente disseminados e contestados, as coberturas serem colocadas em cheque e as redes transformarem-se em espaço de várias dinâmicas jornalísticas, desde o compartilhamento de links noticiosos até a proliferação de outras versões, ou mesmo notícias fakes ou trollagens (Zago, 2012).

As redes sociais passam a ser lugares constitutivos de acontecimentos jornalísticos na medida em que já existem, em grande profusão, acontecimentos que possuem a textura do meio, designados como ciberacontecimentos (Henn, 2013b). Os movimentos de ocupação global, que remetem às mobilizações pioneiras pós-Crise Financeira de 2008 nos EUA, com o Occupy Wall Street, e na Espanha, com o Indignados, e seus vários desdobramentos, como as jornadas de junho de 2013 no Brasil, são exemplares nesse sentido. Boa parte dessas mobilizações são articuladas pelas redes sociais, as narrativas são produzidas in loco pelos próprios participantes e o que é veiculado pela impressa gera

2 Adota-se a designação redes digitais de comunicação para definir o suporte que possibilita a circulação efusiva de mensagens na internet; redes sociais para movimentos de utilização do suporte com fins sociais; e redes, de forma mais ampla, para a ideia de processos que envolvem, necessariamente, mais de um sujeito ou sistema. 
uma grande e instantânea discussão pública, com muitas contestações aos enquadramentos articulados.

A semiose da notícia agora tem outros pontos de propulsão. Chesters e Welsh (2005) assinalam que, dos movimentos de mobilização global emerge um espaço de movimento fractal semelhante às padronizações de auto-similaridade característicos dos sistemas complexos em que os modos simbólicos de contestação, a democracia discursiva e os transbordamentos de conflitos antagônicos nas fronteiras atravessam várias escalas, do local ao global. Essa replicação autopoiética detectada pelos autores, que se espalha hoje (no sentido proposto por Jenkins, Ford e Green, 2013) em outros padrões de semiose (que são essencialmente auto-organizacionais), agenciados pelas redes digitais, está no epicentro da crise ora diagnosticada. Esse processo constitui uma narratividade espalhada, corroborada com acontecimentos que já possuem natureza narrativa, que forma foco de tensões que envolvem, não só o jornalismo (Heinrich, 2011; Russel, 2011), mas todo o sistema midiático contemporâneo.

\section{Jornalismo em contexto de crise}

Na perspectiva dos sistemas abertos, a autopóiese possibilita a emergência de outros sentidos sobre o mundo constantemente. Nos movimentos de ocupação global, essa é uma marca: não há aquela homogeneidade que caracterizou historicamente os movimentos sociais ortodoxos. Por um signo estritamente simbólico, "Ocupai", demandas concretas das mais variadas ordens e localidades tomam forma na semiosfera, significadas, em rede, e repercutem na esfera pública. A possibilidade de significar os acontecimentos e compartilhá-los conferida aos movimentos sociais pelo advento das redes digitais impõem ao jornalismo, como sistema, a necessidade de rever-se, em si, de modo a evitar a entropia total, dando a ver mais da complexidade dos acontecimentos - complexidade que está no cerne da ideia de sistemas abertos e que é característica essencial dos movimentos de organização em rede que ganham protagonismo na esfera pública contemporânea.

As redes sociais formam o ambiente que concretiza essa heterogeneidade e, agora, diferentemente de quando o jornalismo tinha sua condição pouco ameaçada na esfera pública, se constituem como um espaço de disputa de sentidos entre os diferentes sistemas que se dedicam a interpretar o mundo conforme diferentes repertórios e interesses: o sistema social propriamente dito, o sistema capital/mercado, o sistema político... 
Ao jornalismo caberia, numa tentativa despretensiosa de um devir ante a crise, o papel de reafirmar sua função mediadora na semiose (Santaella, 2008) - entre o objeto e o signo, na condição de interpretante que produz o signo/ notícia (Henn, 1996; OLIVEIRA, 2012) -, de modo a escrutinar, entre os sentidos que circulam em rede - e na rede - os significados socialmente mais legítimos.

À outros sistemas restaria, nas suas especificidades, ao significar os acontecimentos, a ação sígnica de fazê-lo conforme seus interesses, explorando essa semiosfera difusa que possibilita que semioses distintas e antagônicas se constituam e repercutam significativamente. É do que decorre a suspeita de que, nessa semiosfera contemporânea, os movimentos sociais podem ocupar espaços importantes, mesmo a partir da mediação do jornalismo, ao tensionálo pelos sentidos que produz em rede, de pressão pelas suas demandas.

No centro do debate, um desafio: o jornalismo precisaria superar o «modelo» calcado em preceitos como objetividade, imparcialidade, instantaneidade, etc. para manter a legitimidade social que the imputa a prerrogativa de mediar a esfera pública (Franciscato, 2005), manter essa outorga; manter-se como sistema que produz certo tipo de conhecimento especifico, que é baseado em convenções e teorizações que historicamente o constituíram, como dedica-se a compreender Meditisch (1997). E postula-se que esse seja um movimento estimulado especialmente pelo ato de assumir sua função mediadora e sua intervenção na construção social da realidade.

Trata-se, ao cabo, da superação dialética de um «modo de fazer» que constituiu o jornalismo por uma simbólica informal, conforme Rodrigues (2000), a partir da outorga a ele conferida por outros sistemas sociais, à uma simbólica formal. Tal qual o sistema jurídico ostenta a toga, ou o sistema político a tribuna, o jornalismo firmaria sua simbólica pela capacidade específica de interpretar os acontecimentos e, ao produzir signos/notícia que os representam, contribuir, como instituição, à construção social da realidade. A função mediadora, metaforicamente, seria a toga do jornalismo.

O jornalismo historicamente, de forma velada - e conforme motivações socialmente pouco legítimas -, procurou sua simbólica formal. Agora, se quiser manter-se como sistema de legitimidade social, terá de enfrentar esse processo às abertas. No campo acadêmico, trata-se de uma batalha que o dá razão de ser - o campo específico do jornalismo como área do conhecimento. E percebese movimentos nesse sentido também no campo profissional; mais até no campo profissional, que oferece um substrato empírico efetivamente concreto. São movimentos instintivos, pouco crítico-reflexivos, mas que expressam 
exemplarmente o momento de crise. É o caso do Profissão Repórter, da TV Globo, localizado na institucionalidade e dos mais notórios.

Há, no referido programa, uma clara reação ao momento em que o jornalismo passa a ser questionado, a partir do "modo de fazer" que o constituiu. Ao revelar, ainda que em parte, os bastidores da reportagem, oferecendo, pretensamente, "outros" sentidos acerca de acontecimentos que ocuparam a agenda do jornalismo hard news, é como se o programa dissesse: "Sabemos que nós, jornalismo, não somos capazes de dizer tudo sobre o mundo, mas nós tentamos dizer tudo o que podemos, conforme as premissas que nos fazem jornalismo". Em Peirce (citado por Santaella, 2008, p. 12): “O signo [...] representa seu objeto. Representa esse objeto não em todos os seus aspectos, mas com referência a um tipo de ideia que eu, por vezes, denominei fundamento do representamen".

\section{Ecos da crise}

Em meio à este cenário de crise, emergem casos que expressam sua face mais concreta e que provocam reflexões ao "modo de fazer" cristalizado pelo jornalismo. Comecemos, pois, tratando de acontecimento que já prestouse à análise de Oliveira e Henn (2013a). Ele remonta à 25 de setembro de 2012: milhares de pessoas nas ruas de Madrid, na Espanha, no "25S", protesto protagonizado pelo Indignados, um dos grupos que aderem aos movimentos de ocupação global e que tem como principal bandeira a democracia real. Uma praça em frente ao Congresso espanhol é ocupada.

O acontecimento é a manifestação do Indignados que mobiliza a sociedade por uma nova constituinte. Presentes estavam índices de notabilidade que definem historicamente o que seja o estatuto do acontecimento jornalístico (Benetti, 2010). E o principal jornal espanhol, o El País (2012a), publica em sua página eletrônica na internet seção especial para as manifestações; para a sua representação como objeto de signos/notícia. Embora as primeiras matérias publicadas abordem o clima de apreensão causado por protestos mais radicais, omitem atos de violência da polícia.

À cobertura do El País concorre, nas redes sociais, denúncias dos próprios manifestantes. No YouTube é publicado vídeo (Dracosp, 2012) em que o garçom Alberto Casillas, funcionário de um bar nas redondezas do Congresso, defende os manifestantes que se refugiam no estabelecimento e impede a entrada dos policiais. A publicação é feita no dia seguinte ao início das manifestações, em 26 de setembro de 2012. 
O vídeo é signo que representa a ação do garçom como objeto, caracteriza-se como um típico exemplo de ciberacontecimento e dispara uma semiose que leva a produção de memes replicados nas redes sociais. O perfil de Casillas no Twitter $^{3}$ ganha um número significativo de seguidores. E com uma breve busca no Facebook encontram-se páginas criadas em sua homenagem ${ }^{4}$.

Uma semiose alternativa àquela das primeiras notícias, que não significavam a violência policial como parte do acontecimento, leva o El País a publicar entrevista com o garçom sob o título "Eu sou do PP, mas a polícia foi excessiva"5 (El País, 2012b). Casillas diz ser eleitor do Partido Popular (PP), conservador e que está no governo, mas que é crítico à ação da polícia, e que por isso defendeu os manifestantes. Pela primeira vez na cobertura do periódico, a violência é significada como parte do acontecimento " 25 ".

Os acontecimentos que compõem o que convencionou-se chamar de jornadas de junho de 2013 no Brasil também são promissores à discussão. Entre os dias 17 e 24 de junho de 2013, Oliveira esteve na redação do jornal Folha de S. Paulo para pesquisa exploratória, parte de investigação mais ampla, empreendida no curso de doutorado, e cujo relato mais completo compõe outro trabalho (Oliveira e Henn, 2013b). A metodologia adotada é de inspiração etnográfica e algumas das inferências são trazidas agora à este texto.

Durante toda a semana, que acabou constituindo-se como auge das manifestações de junho, com mais um milhão de pessoas nas ruas de todo o Brasil no dia 20, observou-se as rotinas de produção da editoria de Cotidiano, que cobria as manifestações em São Paulo e concentrava a publicação de notícias sobre o tema de outras cidades. O que se faz aqui é relatar três das situações observadas que avalia-se sejam as mais férteis à reflexão.

Na segunda-feira, dia 17 de junho, quando começa a observação, em conversa com um dos profissionais da editoria ${ }^{6}$, aparecem indícios sobre como jornalistas percebem as redes sociais: "O Facebook ontem [domingo, dia 16] foi um instrumento de apuração incrível, porque teve protestos [...] no mundo todo". E mais: "No início, achávamos que era só mais uma manifestação.

3 Disponível em: <twitter.com/PorterodelPrado >. Acesso em: 4 jan. 2014.

4 Exemplos ver: <http://www.facebook.com/AnimaAAlbertoCasillasAQuemarSuCarnetDelPp> e $<$ http://www.facebook.com/pages/Hommage-\%C3\%A0-Alberto-Casillas/154936717983883>. Acesso em: 4 jan. 2014.

5 Livre tradução da Língua Espanhola para a Língua Portuguesa.

6 As identidades são preservadas na medida em que interessam os procedimentos-padrão e não a ação desse ou daquele jornalista. 
Começou pelo aumento das passagens e reuniu pessoas com demandas diversas"7.

Ainda na segunda-feira, 17, outro profissional orienta, em reunião, os repórteres sobre como proceder com seus perfis nas redes sociais durante a cobertura dos protestos: "O jornal vai voltar a circular aquela orientação [...]. Vocês são representantes do jornal inclusive nas páginas de vocês. Cuidar pra não comprometer a legitimidade da cobertura", o que denota a preocupação da Folha com as redes como espaço de produção de sentido.

A última passagem observada e aqui relatada refere-se a uma reunião de pauta na quarta-feira, dia 19 de junho. Veja a fala de um dos profissionais da direção da redação: "Tá na cara que a força e a rapidez de mobilização tá calcada nisso [redes sociais]. A maioria fica sabendo por ali [dos protestos], não tá nem aí para o que a gente diz". Fala que revela com riqueza a percepção dos jornalistas do momento de proliferação de semioses que significam os acontecimentos proporcionada pelas redes sociais e que é marca da organização dos movimentos em rede.

\section{Considerações ao debate}

A compreensão sugerida pela reflexão que se encaminha ao final é a de que a postulada crise que atravessa o jornalismo tem, potencialmente, o tensionado a rever suas práticas, com a emergência das redes sociais $e$, por consequência, de uma intensa disputa de sentidos que se estabelece, conforme sugere o esquema abaixo (Figura 1):

Figura 1 - Proposta visual de circulação de sentidos sobre acontecimentos em rede

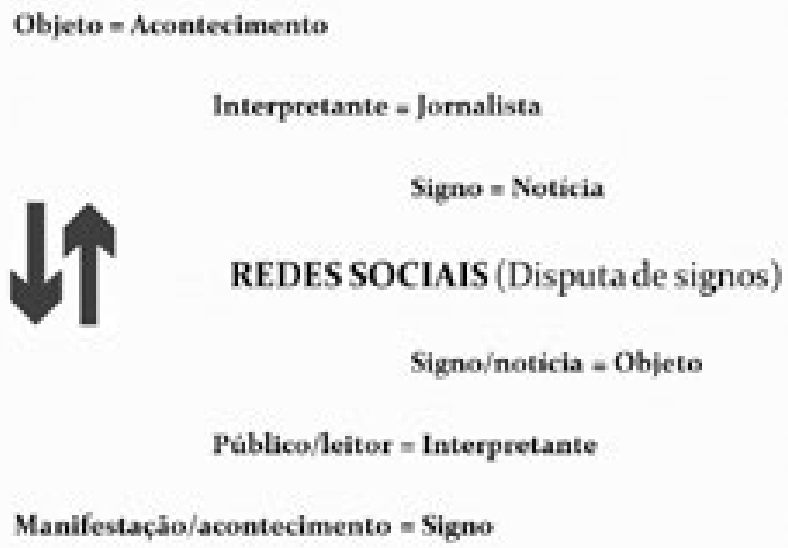

7 As falas de profissionais reproduzidas neste texto são fruto de declarações informais concedidas ao pesquisador ou de diálogos observados. 
E foi justamente com o propósito de fazer funcionar essa compreensão que os casos das manifestações na Espanha e as implicações que tem um ciberacontecimento sobre a semiose da notícia que elas disparam no El País, e a cobertura que a Folha de S. Paulo confere a movimentos em rede que eclodiram no Brasil em 2013, aparecem ao longo da reflexão.

Diante de um ambiente de crise, em que diferentes sistemas de produção de sentido interagem, o jornalismo age no sentido de evitar a entropia total. E ao produzir estratégias de controle dessa entropia, os modos de dar a ver sobre os acontecimentos na esfera pública - ou significa-los na semiosfera - se transformam, fenômeno que circunstancialmente oferece maior visibilidade da sua complexidade.

Como sistema, o jornalismo só existe na interação com outros sistemas, que o afetaram com maior ou menor intensidade ao longo da história. Agora, com as redes sociais, essa afetação é potencializada, gerando o ambiente de crise. A afetação alcança parâmetros críticos e obriga o sistema jornalístico a avançar. À guisa de conclusão, resta o convite para que siga o debate acerca das consequências dessa crise, de modo que se possa aferir de que forma o jornalismo, como sistema de produção de sentido, reorganiza-se e reestruturase. Isso a tal ponto que seja possível saber se sua identidade ressurgirá sob novos parâmetros ou se será, pelo menos, modificada.

\section{Referências}

ANDERSON, P. Complexity Theory and Organization Science. In: Organization Science/Vol. 10, No. 3, May-June 1999, p. 216-232.

BARBOSA, S. Jornalismo Digital em Base de Dados (JDBD). Um paradigma para produtos jornalísticos digitais dinâmicos. (Tese de Doutorado). FACOM/ UFBA, Salvador, 2007.

BARNSLEY, M. Fractals Everywhere, Academic Press, 1998.

BERGÉ, P., POMEAU, Y. e DUBOIS-GANCE, M. Dos ritmos aos caos. São Paulo: Unesp, 1995.

BENETTI, M. O jornalismo como acontecimento. In: BENETTI, M. e FONSECA, V. Jornalismo e Acontecimento: mapeamentos críticos. Florianópolis: Insular, 2010. p. 143-164. 
BUNGE, M. Tratise on basic philosophy - vol. 4: A world of systems. Dordrecht: D. Reidel Publishing Company, 1979.

Sistemas sociales y Filosofia. Buenos Aires: Sudamericana, 1999.

CHARAUDEAU, Patrick. Discurso das mídias. São Paulo: Contexto, 2006.

CHESTERS, G. e WELSH, I. Complexity and Social Movement(s). Process and Emergence in Planetary Action Systems. Theory, Culture \& Society. London, Thousand Oaks and New Delhi: SAGE, vol. 22(5), p. 187-211, 2005.

COLAPIETRO, V. The Routes of Significance: Reflections on Peirce's Theory of Interpretants. In: Cognitio. São Paulo, v. 5, n. 1, p. 11-27, jan./jun. 2004.

DRACOSP. 2012. Disponível em: <http://www.youtube.com/watch?feature=player embedded\&v=pZkmSREGETs\#>. Acesso em: 4 jan. 2014.

EL PAÍS. 2012. Disponível em: <http://politica.elpais.com/tag/manifestacion 25 septiembre 2012/a/>. Acesso em: 4 jan. 2014.

EL PAís. 2012b. Disponível em: <http://ccaa.elpais.com/ccaa/2012/09/26/ madrid/1348680731 595925.html>. Acesso em 4 jan. 2014.

FRANCISCATO, C. A fabricação do presente: como o jornalismo reformulou a experiência do tempo nas sociedades ocidentais. São Cristóvão: Editora UFS/ Fundação Oviedo Teixeira, 2005.

GLEICK, J. Chaos. London: Sphere, 1988.

HARRISON, M. J. Entropy concepts in physics, in Entropy and Information in Science and Philosophy, 1975.

HEINRICH, A. Networked Journalism. Londres: Routledge, 2011.

HENN, R. C. Pauta e notícia. Canoas: Ulbra, 1996.

Os Fluxos da Notícia. São Leopoldo: Unisinos, 2002.

O acontecimento em sua dimensão semiótica. In: BENETTI, M; FONSECA, V. Jornalismo e Acontecimento: mapeamentos críticos. Florianópolis: Insular, p. 77-93, 2010.

A semiodiversidade diante da irreverssibilidade do tempo. In: SILVA, Alexandre Rocha; Nakagawa, Regiane Miranda.. (Org.). Semiótica da Comunicação. São Paulo: Intercom, 1ed., v. 10, p. 102-119, 2013 a. 
O ciberacontecimento. In: VOGEL, D., MEDITSCH, E, e SILVA, G., Jornalismo e acontecimento: tramas conceituais. Florianópolis: Insular, p. 21-34, 2013 b.

KAUFFMAN, S. At home in the universe: the search for laws of selforganization and complexity. New York and Oxford: Oxford University Press, 1995.

JENKINS, H., FORD, S. e GREEN, J., Spreadable Media, Creatin, Value and Meaning in a Networked Culture. Nova York: New York University Press, 2013.

LAFUENTE, G. A melhor maneira de fazer jornalismo é pela internet: entrevista com GumersindoLafuente Parte 1. In: MAROCCO, B. 0 jornalista e a prática: entrevistas. São Leopoldo: Editora Unisinos, p. 211-218, 2012.

LANGER, S. K. Filosofia em nova chave. São Paulo: Perspectiva: 1989.

LATOUR, B. Reensamblar Lo Social: uma introdución a la teoria del actorred. Buenos Aires: Manantial. 2008.

LIEBOVITCH, L. S. Fractals and Chaos Simplied for The Life Sciences, Oxford University: Press, 1998.

LOTMAN, Y. La semiosfera. Madri: Catedra, 1996.

Cultura y explosión, Lo previsible en los processos de cambio social. Barcelona: Gedisa Editorial, 1999.

LOTMAN, Y. USPENSKII, B., et. al. , Ensaios de Semiótica Soviética. Lisboa: Horizonte Universitário, 1981.

LUHMANN, N. Social Systems. Stanford, CA: Stanford University Press, 1995.

MAASEN, S. e WEINGART, P. Metaphors and the Dynamics of Knowledge. London: Routledge, 2000.

MACHADO, E. e PALACIOS, M. (orgs). Modelos de jornalismo digital. Salvador: Calandra, 2003.

MACKENZIE, A. The Problem of the Attractor: A Singular Generality between Sciences and Social Theory. Theory, Culture \& Society. London, Thousand Oaks and New Delhi: SAGE, vol. 22(5), p. 45-65, 2005.

MERRELL, F. Lotman's semiosfhere, Peirces' categories, and cultural forms of life. In: Sign Systems Studies. Rússia e Estônia, v. 29, ed. 2, 2001. 
MEDITSCH, E. O Jornalismo é uma forma de conhecimento?1997. Disponível em: $<$ http://www.bocc.ubi.pt/pag/meditsch-eduardo-jornalismo-conhecimento. pdf>. Acesso: 10 fev. 2014.

MIELNICZUK, L. Jornalismo na web: uma contribuição para o estudo do formato da notícia na escrita hipertextual. Tese (Douturado em Comunicação e Cultura). Universidade Federal da Bahia, Salvador, BA, 2003.

MORIN, E. O enigma do homem. Rio de Janeiro: Zahar, 1975.

O Método I - A natureza da natureza. Mira-Sintra: Europa-América, 1986a.

O Método II - A vida da vida. Mira-Sintra: Europa-América, 1986b.

O Método III - A consciência da consciência. Mira-Sintra: Europa-América, 1986c.

O Método IV - As ideias. Habitat, vida, costumes, organização. Porto Alegre: Sulina, 1998.

MORIN, E. e PIATTELI-PALMARINI, M. A unidade do Homem. Vol 3. São Paulo: Cultrix, 1975.

NOWOTMY, H. The Increase of Complexity and its Reduction. Emergent Interfaces between the Natural Sciences, Humanities and Social Sciences. Theory, Culture \& Society. London, Thousand Oaks and New Delhi: SAGE, v. 22, n. 5, p. 15-31, 2005.

OLIVEIRA, F. M. Produção da notícia e movimentos sociais: processos de produção no Jornalismo. 2012. 286f. Dissertação (Mestrado em Ciências da Comunicação). Unisinos, São Leopoldo, RS, 2012.

OLIVEIRA, F. M. e HENN, R. C. Jornalismo, redes sociais e movimentos de ocupação global: uma crise sistêmica na semiosfera contemporânea. In: Anais do II Colóquio Internacional Mudanças Estruturais no Jornalismo - Mejor 2013, p. 443-456, $2013 a$.

Movimentos em rede e ocupação do espaço público: limites e possibilidades antes a crise do jornalismo. In: Anais do 110 Encontro Nacional de Pesquisadores em Jornalismo (SBPJor), Brasília, 2013b.

PALÁCIOS, M. e NOCl, J. D. Ciberperiodismo: métodos de investigación: Una aproximación multidisciplinar em perspectiva comparada. Servicio Editorial de la Universidad del País Vasco, 2009. Disponível em: <http://www. ehu.es/argitalpenak/images/stories/libros gratuitos en pdf/Ciencias Sociales/Ciberperiodismo\%20\%20Metodos\%20de\%20investigacion.pdf>, Acesso em: 10 fev. 2014. 
PEIRCE, C. S. The Collected Papers of Charles Sanders Peirce. Past Masters, CD-ROM. InteLex Corporation: EUA, 2002.

PRIGOGINE, I. Order trough Fluctuation: Self-Organization in Social System. In: Evolution an Consciousness: Human Systems in Transition. Jantsch, E. and Waddington, C. H. (eds.), p. 93-126. Massachusetts. Addison-Wesly Publ. Company, 1976.

O fim das certezas: tempo, caos e as leis da natureza. São Paulo: Unesp, 1996.

PRIGOGINE, I. e STENGERS. Order out of Chaos. Heinemann: London, 1984.

RAMONET, I. A explosão do jornalismo. Das mídias de massa à massa de mídias. São Paulo: Publisher Brasil, 2012.

RODRIGUES, A. D. Experiência, modernidade e campo dos média. In: SANTANA, R. N. M. (Org). Reflexões sobre o mundo contemporâneo. Rio de Janeiro: Revan, 2000, p. 169-214.

RUSSELL, A. Networked, a Contemporary History of News in Transition. Cambridge: Polity Press, 2011.

SANTAELLA, L. A Teoria Geral dos Signos: como as linguagens significam as coisas. São Paulo: Cengae Learning, 2008.

SOMMERFELD, P. e HOLLENSTEIN, L. Searching for Appropriate Waysto Face the Challenges of Complexity and Dynamics, in British Journal of Social Work, v. 41, p. 668-688, 2011.

STEWART, I. Does God Play Dice? The Mathematics of Chaos. Oxford: Basil Blackwell, 1989.

SUROWIECKI, J. The Wisdom of Crowds. London: Little Brown, 2004.

SCHWINGEL, C. Ciberjornalismo. São Paulo: Paulinas, 2012.

URRY, J., The Complexity Turn. Theory, Culture \& Society. London, Thousand Oaks and New Delhi: SAGE, vol. 22, n. 5, p. 1-14, 2005.

ZAGO, G., Recirculação jornalística no twitter: filtro e comentário de notícias por interagentes como uma forma de potencialização da circulação. Dissertação (Mestrado em Comunicação e Informação). UFRGS, Porto Alegre, RS, 2011. 
Recebido em: 6/5/2015

Aceito em: 30/6/2015

\section{Endereço dos autores}

Ronaldo Cesar Henn <henn.ronaldo@gmail.com>

Rua Augusto Pestana, 25/91

CEP: $90040-200$

Porto Alegre/RS - Brasil

Felipe Moura de Oliveira <felipecomunica@gmail.com>

Rua Fredolino de Souza Soares, 120 - Boa Saúde

CEP: 93347-215

Novo Hamburgo/RS - Brasil 